\title{
Identification of a cyclic-di-GMP-modulating response regulator that impacts biofilm formation in a model sulfate reducing bacterium
}

\author{
Lara Rajeev $^{1+}$, Eric G. Luning ${ }^{1+}$, Sara Altenburg ${ }^{2}$, Grant M. Zane ${ }^{3}$, Edward E. K. Baidoo ${ }^{1}$, \\ Michela Catena ${ }^{1}$, Jay D. Keasling ${ }^{1,4}$, Judy D. Wall ${ }^{3}$, Matthew W. Fields ${ }^{2,5}$ and \\ Aindrila Mukhopadhyay ${ }^{1 *}$ \\ 1 Physical Biosciences Division, Lawrence Berkeley National Laboratory, Berkeley, CA, USA \\ ${ }^{2}$ Center for Biofilm Engineering, Montana State University, Bozeman, MT, USA \\ ${ }^{3}$ Department of Biochemistry, University of Missouri, Columbia, MO, USA \\ ${ }^{4}$ Department of Chemical and Biomolecular Engineering, Department of Bioengineering, University of California, Berkeley, CA, USA \\ ${ }^{5}$ Department of Microbiology and Immunology, Montana State University, Bozeman, MT, USA
}

\section{Edited by:}

Luis Raul Comolli, Lawrence

Berkeley National Laboratory, USA

Reviewed by:

Xiuzhu Dong, Chinese Academy of

Sciences, China

Michael Y. Galperin, National

Institutes of Health, USA

*Correspondence:

Aindrila Mukhopadhyay, Lawrence Berkeley Lab, 1 Cyclotron Road MS-978-4121, Berkeley, CA 94720, USA

e-mail:amukhopadhyay@lbl.gov

tThese authors have contributed equally to this work.
We surveyed the eight putative cyclic-di-GMP-modulating response regulators (RRs) in Desulfovibrio vulgaris Hildenborough that are predicted to function via two-component signaling. Using purified proteins, we examined cyclic-di-GMP (c-di-GMP) production or turnover in vitro of all eight proteins. The two RRs containing only GGDEF domains (DVU2067, DVU0636) demonstrated c-di-GMP production activity in vitro. Of the remaining proteins, three RRs with HD-GYP domains (DVU0722, DVUA0086, and DVU2933) were confirmed to be $\mathrm{Mn}^{2+}$-dependent phosphodiesterases (PDEs) in vitro and converted c-di-GMP to its linear form, pGpG. DVU0408, containing both c-di-GMP production (GGDEF) and degradation domains (EAL), showed c-di-GMP turnover activity in vitro also with production of $\mathrm{pGpG}$. No c-di-GMP related activity could be assigned to the RR DVU0330, containing a metal-dependent phosphohydrolase HD-OD domain, or to the HD-GYP domain RR, DVU1181. Studies included examining the impact of overexpressed cyclic-di-GMP-modulating RRs in the heterologous host $E$. coli and led to the identification of one RR, DVU0636, with increased cellulose production. Evaluation of a transposon mutant in DVU0636 indicated that the strain was impaired in biofilm formation and demonstrated an altered carbohydrate:protein ratio relative to the $D$. vulgaris wild type biofilms. However, grown in liquid lactate/sulfate medium, the DVU0636 transposon mutant showed no growth impairment relative to the wild-type strain. Among the eight candidates, only the transposon disruption mutant in the DVU2067 RR presented a growth defect in liquid culture. Our results indicate that, of the two diguanylate cyclases (DGCs) that function as part of two-component signaling, DVU0636 plays an important role in biofilm formation while the function of DVU2067 has pertinence in planktonic growth.

Keywords: cyclic-di-GMP, biofilm, Desulfovibrio, HD-GYP, GGDEF, GGDEF-EAL, response regulator, twocomponent system

\section{INTRODUCTION}

Many inter- and intra- species interactions are mediated by small molecule signals. Of these, cyclic-di-GMP (c-di-GMP) has come to be recognized as a ubiquitous second messenger in bacteria. Discovered in 1987 in Gluconacetobacter xylinus, the first established function of c-di-GMP was in the allosteric activation of a cellulose synthase for the biosynthesis of extracellular cellulose (Ross et al., 1987). C-di-GMP is now known to play a role in a large number of phenotypes ranging from attachment, motility, biofilm formation, quorum sensing to numerous other developmental, pathogenic, and virulence responses (for a recent review see Romling et al., 2013). In general, accumulation of c-di-GMP results in greater sessility, attachment and improved biofilm formation, while reduction of the same results in greater motility and other associated growth characteristics (Simm et al., 2004). Not surprisingly, enzymes that modulate c-di-GMP levels have been annotated in most bacteria (Galperin et al., 2010) and have been well reviewed (Hengge, 2009; Schirmer and Jenal, 2009). Levels of c-di-GMP in the cell are modulated through the function of GGDEF motif-containing proteins that act as diguanylate cyclases (DGCs) with GTP as substrate (Paul et al., 2004; Ryjenkov et al., 2005), and EAL (Ross et al., 1987; Simm et al., 2004; Schmidt et al., 2005) or HD-GYP motif-containing proteins (Ryan et al., 2006; Stelitano et al., 2013) that act as phosphodiesterases (PDEs) that degrade c-di-GMP to pGpG or GMP (Figure 1A).

C-di-GMP modulating domains are most commonly found in combination with other signaling domains, such as PAS or GAF, or as output domains in the receiver portion of two-component 


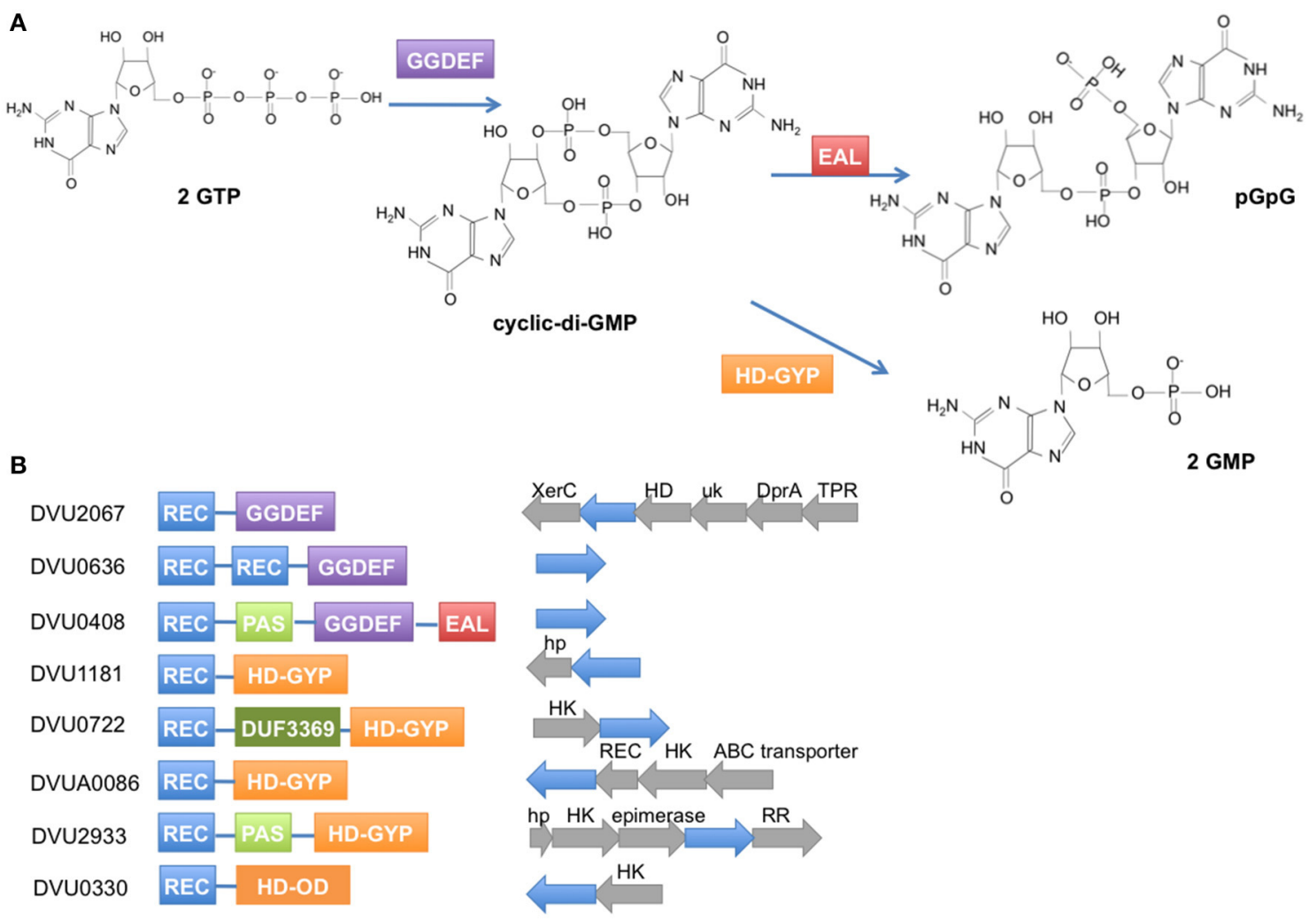

C

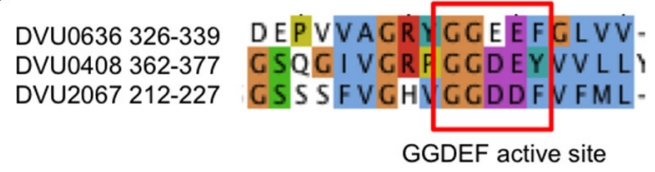

DVU0330 259-278 RDNALSACLLHDVC C LALAA DVU0722 365-382 VAMLR I ASPMHDVG C I G I - DVUA0086 193-210 CDLLGECAP LHDVG C I G I - DVU2933 311-328 I EGVRVAAMLHD I C C I H I - DVU1181 205-222 LDGLRVAAT LHDI C C LCI - -

HDIG active site

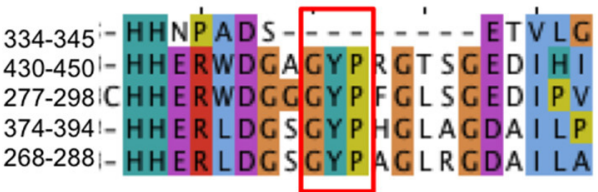

GYP conserved site
FIGURE 1 | Response regulators in D. vulgaris Hildenborough with GGDEF, EAL, and HD domains. (A) The GGDEF domain synthesizes c-di-GMP from GTP, while the EAL and HD-GYP domains hydrolyze c-di-GMP to $p G p G$ and GMP, respectively. (B) Domain structures are shown for the 2 GGDEF domain RRs, 1 GGDEF-EAL RR, 4 HD-GYP RRs, and 1 HDOD RR ( $R E C=$ receiver domain). To the right of the domain structures are shown the operon arrangements of each RR with the RR gene shown in blue.
(Abbreviations: XerC, integrase domain; HD, HD domain; uk, unknown domain; DprA, DNA processing protein A; TPR, Tetratricopeptide domain protein; hp, hypothetical protein; HK, histidine kinase; REC, receiver domain). (C) Amino acid sequence alignment of the conserved active site residues for the GGDEF domain RRs (top) and the HD domain RRs (bottom). Note that DVU0408 has a $Y$ instead of the conserved $F$ in its GGDEF domain. Also DVU0330 is an HDOD domain that lacks the GYP motif. system response regulators (RRs) (Romling et al., 2013). Signaling systems that use second messenger signaling are critical to survival in different environments and provide a competitive advantage to biological systems under different environmental constraints. However, few such sets of enzymes have been functionally explored (Solano et al., 2009; Wang et al., 2010; Tan et al., 2014).

Here we examine all presumptive c-di-GMP-modulating RRs that are part of two-component signaling in the sulfate-reducing bacterium Desulfovibrio vulgaris Hildenborough. Sequenced in 2003 (Heidelberg et al., 2004), this bacterium serves as a model organism to study sulfate reduction and carbon oxidation as well as metal reduction (Beyenal et al., 2004), metal corrosion (Lee et al., 1995), biofilm formation (Clark et al., 2012), and bioimmobilization in superfund sites (Faybishenko et al., 2008). D. vulgaris Hildenborough has been extensively studied for a variety of stress responses (Zhou et al., 2011), syntrophic interactions (Hillesland and Stahl, 2010), regulatory motifs (Rodionov et al., 
2004; Kazakov et al., 2013b), and signal transduction (Rajeev et al., 2011). The genome of $D$. vulgaris Hildenborough has a high "microbial sensory IQ" (Galperin et al., 2010) encoding a total of 41 genes containing GGDEF/EAL/HD-GYP domains. Of these, eight are linked to two-component system response regulator receiver domains (Figure 1B) and none have been functionally characterized. We used purified proteins to evaluate the predicted function of all eight candidates. We also conducted in vivo assays to test certain phenotypes that are known to be associated with c-di-GMP modulation. We identified DVU0636 to be involved in biofilm formation in D. vulgaris Hildenborough.

\section{MATERIALS AND METHODS CLONING OF RESPONSE REGULATOR GENES}

Full-length genes for the eight RRs were cloned by Gateway technology into the destination vector pETDEST42 (Life Technologies, Grand Island, NY, USA) as previously described (Rajeev et al., 2011), such that the protein is expressed with a C-terminal V5 epitope and 6X-His tag. The HD-GYP domains of DVUA0086 (164-363 aa) and DVU2933 (282-458 aa) were cloned into pSKB3 $\left(\mathrm{Kan}^{\mathrm{R}}\right)$ with an N-terminal cleavable 6X-His tag. The HD-GYP domains of DVU1181 (176-356 aa), DVU0722 (336-518 aa) and DVU0330 (230-412) were cloned into pSKB3 with a cleavable N-terminal $8 \mathrm{x}$-His-tag, Strep Tag II, and a maltose binding protein tag. The genes were amplified from D. vulgaris Hildenborough genomic DNA with iProof HiFidelity polymerase (BioRad, Hercules, CA, USA) and primers that were designed to have $40 \mathrm{bp}$ overlap between the insert and the vector backbone. The vector was similarly amplified and treated with DpnI, followed by agarose gel extraction and purification. The vector and insert were mixed in a 1:1 molar ratio and assembled with a modified Gibson reagent (Gibson et al., 2009) that lacked the Taq ligase. The Gibson reaction was used to transform E. coli BL21 (DE3) electrocompetent cells and transformants were selected on Yeast Tryptone agar plates with kanamycin ( $50 \mu \mathrm{g} / \mathrm{ml}$ ). The presence of the insert was verified by sequencing. Note on DVU2067 cloning: Sequencing of the cloned DVU2067 revealed an extra 39 bp sequence at the C-terminus that appeared to be a repetition of the last 19-20 bp of the gene.

\section{PROTEIN OVEREXPRESSION}

Expression constructs were grown in $10 \mathrm{ml}$ Terrific Broth (TB) (Tartof and Hobbs, 1987) containing kanamycin $(50 \mu \mathrm{g} / \mathrm{ml})$ at $37^{\circ} \mathrm{C}$ until an $\mathrm{OD}_{600}$ of 1.5 . Protein expression was induced with $0.25 \mathrm{mM}$ IPTG, and cells were grown at $22^{\circ} \mathrm{C}$ overnight. The cells were harvested, resuspended in $1 \times$ PBS buffer and lysed by sonication. The lysates were centrifuged at $15,000 \times g$ for $30 \mathrm{~min}$ at $4^{\circ} \mathrm{C}$. The clarified lysate was examined for protein overexpression by SDS-PAGE followed by Western blotting with mouse anti-His monoclonal antibodies.

\section{PROTEIN PURIFICATION}

The expression strain was grown in $1 \mathrm{~L}$ of TB with kanamycin $(50 \mu \mathrm{g} / \mathrm{ml})$ at $37^{\circ} \mathrm{C}$ until $\mathrm{OD}_{600}$ of 1.5 . IPTG $(0.25 \mathrm{mM})$ was added and cells were grown at $22^{\circ} \mathrm{C}$ overnight. Cells were harvested and lysed by sonication in $150 \mathrm{ml}$ of cold Buffer A $(20 \mathrm{mM}$ sodium phosphate, $0.5 \mathrm{M} \mathrm{NaCl}, 40 \mathrm{mM}$ imidazole, $\mathrm{pH} 7.4$ ) with lysozyme $(1 \mathrm{mg} / \mathrm{ml})$ and $1 \times$ benzonase nuclease (New England Biolabs, Ipswich, MA, USA). Lysate was clarified by centrifugation at $15,000 \times g$ for $30 \mathrm{~min}$ at $4^{\circ} \mathrm{C}$ and filtered on a $0.45-\mu \mathrm{m}$ poresized syringe filter. The lysate was loaded onto a $5 \mathrm{ml}$ HisTrapFF column (GE Life Sciences, Piscataway, NJ) in an Akta Explorer 100 FPLC instrument (GE Life Sciences, Piscataway, NJ) and eluted with a gradient of $0-100 \%$ Buffer B (20 mM sodium phosphate, $0.5 \mathrm{M} \mathrm{NaCl}, 500 \mathrm{mM}$ imidazole, $\mathrm{pH} 7.4$ ) over $30 \mathrm{~min}$ with a flow rate of $2 \mathrm{ml} / \mathrm{min}$. Purified fractions were pooled and buffer exchanged on a 26/10 desalting column (GE Life Sciences) into a desalting buffer $(20 \mathrm{mM}$ sodium phosphate $\mathrm{pH} 7.4,300 \mathrm{mM}$ $\mathrm{NaCl})$. The tags were removed by incubating overnight with purified His-tagged TEV protease at $4^{\circ} \mathrm{C}$ with rocking. The TEV protease, cleaved tags, and uncleaved proteins were removed by passing the mixture through a $5 \mathrm{ml}$ HisTrapFF column. Tagless proteins were buffer exchanged on a $26 / 10$ desalting column into $20 \mathrm{mM}$ Tris- $\mathrm{HCl} \mathrm{pH} 8.0$ and $20 \mathrm{mM} \mathrm{NaCl}$. Proteins were concentrated to $\sim 0.5-1 \mathrm{mg} / \mathrm{ml}$, glycerol was added to $10 \%$ ( $\mathrm{vol} / \mathrm{vol}$ ), aliquots were flash frozen in liquid nitrogen and stored at $-80^{\circ} \mathrm{C}$.

For the HD-GYP domains of DVU1181, DVU0722, and DVU0330, a second round of affinity purification was performed by eluting from the first HisTrapFF column onto a $5 \mathrm{ml}$ StrepTrapFF (GE Life Sciences). The column was washed with Buffer C (20 mM sodium phosphate $\mathrm{pH}$ 7.4, $280 \mathrm{mM} \mathrm{NaCl}, 6 \mathrm{mM}$ $\mathrm{KCl}$ ) and eluted with Buffer $\mathrm{D}$ (Buffer $\mathrm{C}+2.5 \mathrm{mM}$ desthiobiotin). Then, $50 \mathrm{mM}$ L-arginine and $50 \mathrm{mM}$ L-glutamic acid buffered in Tris- $\mathrm{HCl}$ were added to stabilize proteins (Golovanov et al., 2004). This was followed by TEV cleavage and purification of tagless protein as described above.

\section{DGC ASSAY FOR DVU0636, DVU2067, AND DVU0408}

Full length DVU0636, DVU2067, and DVU0408 with a C-terminal V5 epitope and 6x His tag were purified from E. coli. Purified protein $(1.6-1.8 \mu \mathrm{M})$ was mixed with $0.5 \mathrm{mM}$ GTP in $50 \mathrm{mM}$ Tris $\mathrm{HCl} \mathrm{pH} 8.0,100 \mathrm{mM} \mathrm{NaCl}$, and either $2 \mathrm{mM} \mathrm{MgCl}_{2}$ or $2 \mathrm{mM} \mathrm{MnCl}_{2}$ in a total volume of $100 \mu \mathrm{l}$. The reactions were incubated at $30^{\circ} \mathrm{C}$ for $24 \mathrm{~h}$. The proteins were denatured by heating at $95^{\circ} \mathrm{C}$ for $5 \mathrm{~min}$. The samples were centrifuged at 15,000 $\times$ $g$ for $10 \mathrm{~min}$, and the supernatant was filtered through a $10 \mathrm{~K}$ molecular weight cutoff centrifugal filter prior to HPLC analysis. Samples $(3 \mu \mathrm{l})$ were injected into an Inertsil ODS-3 column $(3 \mu$, $250 \times 2.1 \mathrm{~mm}$; GL Sciences, Torrance, CA) equipped with a guard column (Inertsil ODS-3, $3 \mu, 50 \times 2.1 \mathrm{~mm}$; GL Sciences) on an HPLC system (Agilent Technologies, Santa Clara, CA). Buffer A: $100 \mathrm{mM}$ Potassium phosphate buffer $\mathrm{pH}$ 6.0; Buffer $\mathrm{B}=100 \%$ ( $\mathrm{vol} / \mathrm{vol}$ ) methanol. The samples were run for $25 \mathrm{~min}$ at a flow rate of $0.2 \mathrm{ml} / \mathrm{min}$, with the following gradient: $0 \mathrm{~min}-2 \%$ ( $\mathrm{vol} / \mathrm{vol}$ ) B; 2 min $-2 \% \mathrm{~B} ; 14 \mathrm{~min}-30 \% \mathrm{~B} ; 17 \mathrm{~min}-30 \% \mathrm{~B} ; 18 \mathrm{~min}-2 \%$ B; $25 \mathrm{~min}-2 \% \mathrm{~B}$.

\section{PDE ACTIVITY ASSAY: WITH bis-pNPP}

Triplicate enzyme reactions for each protein were set up in a 96well microplate (Costar, black with clear flat bottom, polystyrene; Corning Incorporated, Corning, NY). Proteins (7-10 $\mu$ g) were mixed in a total volume of $100 \mu \mathrm{l}$ with $5 \mathrm{mM}$ bis- $p$ NPP in $25 \mathrm{mM}$ Tris- $\mathrm{HCl} \mathrm{pH}$ 8.0, $100 \mathrm{mM} \mathrm{NaCl}, 1 \mathrm{mM}$ DTT, and either 1 or $10 \mathrm{mM} \mathrm{MnCl}_{2}$ or $10 \mathrm{mM} \mathrm{MgCl}_{2}$. Absorbance was measured 
at $410 \mathrm{~nm}$ every $10 \mathrm{~min}$ in a SpectraMax Plus plate reader (Molecular Devices, Sunnyvale, CA, USA). A reaction that lacked bis- $p$ NPP served as the blank, while a reaction with no protein served as a negative control.

\section{PDE ACTIVITY ASSAY: WITH c-di-GMP}

Each protein $(7-10 \mu \mathrm{g})$ was mixed with $100 \mu \mathrm{M}$ c-di-GMP in $25 \mathrm{mM}$ Tris $\mathrm{HCl} \mathrm{pH} 8.0,10 \mathrm{mM} \mathrm{MnCl}_{2}, 100 \mathrm{mM} \mathrm{NaCl}, 1 \mathrm{mM}$ DTT in a total volume of $100 \mu$ l HPLC grade water. Reactions were carried out in triplicate and incubated at room temperature for $24 \mathrm{~h}$. The reactions were stopped and proteins denatured by heating to $95^{\circ} \mathrm{C}$ for $5 \mathrm{~min}$. The samples were centrifuged at $15,000 \times g$ for $10 \mathrm{~min}$, and the supernatant was filtered through a $10 \mathrm{~K}$ molecular weight cutoff spin filter before HILIC-TOF MS (hydrophilic interaction liquid chromatography and time of flight mass spectrometry) analysis. The proteins were also tested for activity against $100 \mu \mathrm{M}$ of cyclic-di-AMP, cyclic-AMP, cyclicGMP, and pGpG. Samples were injected onto a SeQuant Zic pHILIC $(150 \mathrm{mM}$ length $\times 2.1 \mathrm{mM}$ diameter column together with a $20 \times 2.1 \mathrm{mM}$ Zic pHILIC guard column; EMD Millipore, Billerica, MA, USA). For a full description of the analytical method, please refer to Bokinsky et al. (2013).

\section{CONGO RED E. COLI ASSAY}

E. coli BL21 Star DE3 strains expressing the full-length RR genes were grown overnight in $3 \mathrm{ml}$ LB containing carbenicillin $(100 \mu \mathrm{g} / \mathrm{ml})$. Each strain was diluted $1: 100$ in fresh medium, grown until $\mathrm{OD}_{600}$ of 0.5 at $37^{\circ} \mathrm{C}$, and then streaked out on LB-carbenicillin plates containing Congo Red (CR) $5 \mu \mathrm{g} / \mathrm{ml}$ ( $\pm 0.5 \mathrm{mM}$ IPTG). Plates were incubated at room temperature for 4 days.

\section{TRANSPOSON MUTANT LIBRARY}

The transposon mutants were obtained from the D. vulgaris transposon mutant collection (Zane and Wall, 2013) constructed at the University of Missouri, which have been used in other studies (Fels et al., 2013; Kazakov et al., 2013a; Ray et al., 2014). Strain descriptions are provided in Table 1.

\section{GROWTH ASSAYS FOR D. VULGARIS STRAINS}

D. vulgaris was grown in a defined medium containing $8 \mathrm{mM}$ $\mathrm{MgCl}_{2}, 20 \mathrm{mM} \mathrm{NH}_{4} \mathrm{Cl}, 2.2 \mathrm{mM} \mathrm{K}_{2} \mathrm{PO}_{4}, 0.6 \mathrm{mM} \mathrm{CaCl}_{2}, 30 \mathrm{mM}$ Tris, $1 \mathrm{ml} /$ liter of Thauer's vitamins (Brandis and Thauer, 1981),

Table 1 | Transposon mutant strains used in this study.

\begin{tabular}{ll}
\hline Name & Description \\
\hline GZ0620 & DVU0330-496::Tn5-RL27; insertion at bp 496/1239; $\mathrm{Km}^{r}$ \\
GZ2490 & DVU2067-828::Tn5-RL27; insertion at bp 828/1122; $\mathrm{Km}^{r}$ \\
GZ3062 & DVU0636-506::Tn5-RL27; insertion at bp 506/1314; $\mathrm{Km}^{r}$ \\
GZ4281 & DVU0408-857::Tn5-RL27; insertion at bp 857/2148; $\mathrm{Km}^{r}$ \\
GZ4944 & DVU1181-479::Tn5-RL27; insertion at bp 479/1071; Km \\
GZ5161 & DVUA0086-105::Tn5-RL27; insertion at bp 105/1092; Km \\
GZ5218 & DVU0722-279::Tn5-RL27; insertion at bp 279/1557; $\mathrm{Km}^{r}$ \\
GZ2493 & DVU2933-215::Tn5-RL27; insertion at bp 215/1377; $\mathrm{Km}^{r}$
\end{tabular}

$12.5 \mathrm{ml} /$ liter of trace element solution (Rajeev et al., 2012), $640 \mu \mathrm{l} /$ liter of resazurin $(0.1 \% \mathrm{wt} / \mathrm{vol})$, and supplemented with $50 \mathrm{mM}$ $\mathrm{Na}_{2} \mathrm{SO}_{4}$ and $60 \mathrm{mM}$ sodium lactate (LS4D medium). The $\mathrm{pH}$ of the medium was adjusted to 7.2 with $1 \mathrm{~N} \mathrm{HCl}$. Cultures were grown at $30^{\circ} \mathrm{C}$ in an anaerobic growth chamber (COY Laboratory Products, Grass Lake, MI, USA) in an atmosphere of $85 \% \mathrm{~N}_{2}$, $10 \% \mathrm{CO}_{2}$, and $5 \% \mathrm{H}_{2}$. For transposon mutants, the medium was supplemented with the antibiotic G418 (400 $\mu \mathrm{g} / \mathrm{ml})$ (Sigma Aldrich, St. Louis, MO, USA). D. vulgaris strains were grown from freezer stocks in LS4D supplemented with $0.1 \%$ (wt/vol) yeast extract in $15 \mathrm{ml}$ centrifuge tubes and then transferred to LS4D medium with a $2 \%(\mathrm{vol} / \mathrm{vol})$ inoculum. $400 \mu \mathrm{l}$ of cultures were transferred ( 4 replicates each) into 100 -well honeycomb well plates (Growth Curves USA, Piscataway, NJ, USA) and growth measurements were conducted on the Bioscreen $\mathrm{C}$ instrument (Growth Curves USA, Piscataway, NJ, USA) at $30^{\circ} \mathrm{C}$ within the anaerobic chamber.

\section{COMPLEMENTATION OF Tn5::DVU0636}

DVU0636 was cloned into the E. coli-D. vulgaris shuttle vector pMO9075 (Keller et al., 2014) under a constitutive kanamycin promoter, and with a C-terminal His-tag. Strain GZ3062 (Tn5::DVU0636) was grown overnight from a freezer stock in $10 \mathrm{ml}$ MOYLS4 (+G418). Five milliliter of the overnight culture was used to inoculate $45 \mathrm{ml}$ of fresh MOYLS4 (+G418) and allowed to grow overnight. Electrocompetent cells were prepared as previously described (Zane et al., 2010), and cells $(50 \mu \mathrm{l})$ were transformed with pMO9075::DVU0636. Transformants were allowed to recover in $1 \mathrm{ml}$ MOYLS4 overnight and then were plated on MOYLS4 containing spectinomycin $(100 \mu \mathrm{g} / \mathrm{ml})$. Colonies were obtained after 4-5 days. Colonies were inoculated into $1 \mathrm{ml}$ MOYLS4 (+G418 and spectinomycin), grown overnight, and transferred to $5 \mathrm{ml}$ MOYLS4 (+G418 and spectinomycin). The resulting culture was used for plasmid preparations and to make freezer stocks. The plasmids were verified by sequencing and the complemented strain was designated as GZ3062(pMO9075::DVU0636).

\section{BIOFILM ASSAYS}

Frozen stocks of D. vulgaris Hildenborough WT (from Montana State University), GZ3062, and the complemented strain were grown to approximately $0.6 \mathrm{OD}_{600}$ in LS4D medium before transfer. The mutant and complement were maintained under appropriate antibiotics for the duration of the study. Once transferred, the cells were again grown to $0.6 \mathrm{OD}_{600}$ before inoculation (approximately 10\% vol/vol inoculum) into the biofilm reactor. The culture was allowed to grow for approximately $24 \mathrm{~h}$ before constant medium flow was introduced at a dilution rate of $0.10 \mathrm{~h}^{-1}$. Biofilm samples were grown in a CDC biofilm reactor (Biosurface Technologies, Bozeman, MT, USA) at $30^{\circ} \mathrm{C}$ in LS4D under constant sparging $(\sim 0.85 \mathrm{kPa} / \mathrm{min})$ with anoxic $\mathrm{N}_{2}$ as previously described (Clark et al., 2012). Coupon holders fitted with glass microscope slides (cut in half) were removed at approximately $120 \mathrm{~h}$, and samples were washed with chilled phosphate buffered saline ( $50 \mathrm{mM}$ phosphate, $0.7 \% \mathrm{NaCl}, \mathrm{pH} 7.2$ ) to remove loosely attached cells. The biofilm was then scraped from each slide into sterile tubes and stored at $-80^{\circ} \mathrm{C}$. Biofilm samples for 
electron microscopy were treated as previously described (Clark et al., 2007). Glass slide sections were mounted on aluminum stubs, coated with iridium, and viewed on a SUPRA 55VP field emission scanning electron microscope (Carl Zeiss Microscopy, Peabody, MA, USA) at $1.0 \mathrm{kV}$. To determine carbohydrate and protein levels for the different cultures, hexose sugars were measured by the colorimetric cysteine-sulfuric acid method with glucose as the standard (Chaplin, 1986). Protein was measured with the Qubit ${ }^{\circledR}$ Protein Assay Kit (Life Technologies, Grand Island, NY, USA) and Qubit ${ }^{\circledR}$ Fluorometer (Life Technologies, Grand Island, NY, USA) according to the manufacturer's instructions.

\section{RESULTS}

\section{BIOCHEMICAL ANALYSIS OF THE c-di-GMP MODULATING RRs}

In order to confirm the putative functions of the annotated RRs with c-di-GMP modulating domains, genes encoding the eight RRs were cloned into E. coli, the encoded proteins produced and purified.

DVU0636 and DVU2067 have DGC activity, DVU0408 has PDE activity The three RRs with GGDEF domains were subjected to DGC activity assays by incubation with GTP followed by HPLC analysis (Figures 2, 3).

Purified tagged full length DVU0636 protein converted nearly all of the GTP into c-di-GMP within $24 \mathrm{~h}$ of incubation with $\mathrm{Mg}^{+2}$ ions (2 mM) (Figure 2A). Interestingly when incubated with $\mathrm{Mn}^{+2}$ ions $(2 \mathrm{mM})$, although the GTP was completely consumed, other peaks were present in addition to that of c-di-GMP (Figure 2B). We suspect that these are secondary products rather than reaction intermediates since incubation of the reaction with $\mathrm{Mg}^{+2}$ for a shorter time $(4 \mathrm{~h})$ did not produce these intermediate

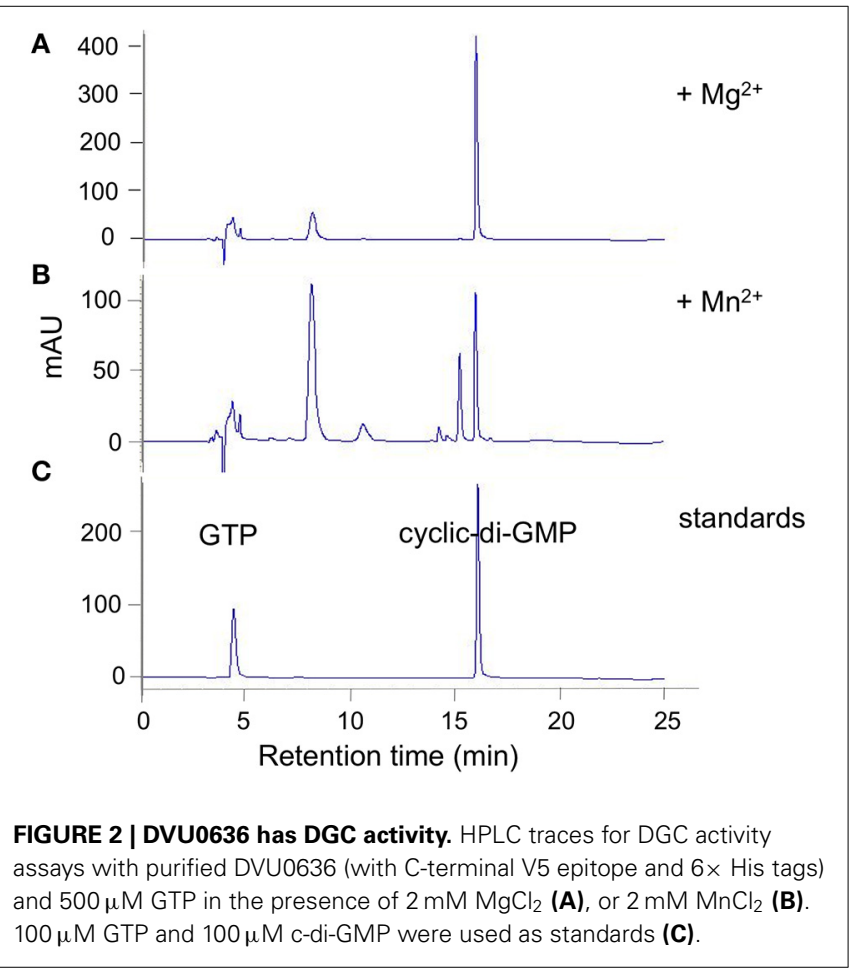

peaks (except for a small peak at $8 \mathrm{~min}$ ), and extending the incubation time with $\mathrm{Mn}^{+2}$ to $40 \mathrm{~h}$ still resulted in the alternate product peaks (not shown). No product formed in the absence of either $\mathrm{Mg}^{+2}$ or $\mathrm{Mn}^{+2}$.

When full length purified tagged DVU2067 protein was incubated with GTP, there was very little product formed with either $\mathrm{Mn}^{+2}$ or $\mathrm{Mg}^{+2}$ ions. The small peak seen appears to be c-di-GMP as it was absent when no metal ions were added to the reaction (Figure 3). The addition of acetyl phosphate to stimulate phosphorylation did not increase the activity of either DVU0636 or DVU2067 (not shown).

Purified full length DVU0408 protein possessed no detectable DGC activity (not shown). However, it did have PDE activity against c-di-GMP (Figure 4). The amount of product, $5^{\prime}$-pGpG, was greater with $\mathrm{Mn}^{+2}$ than with $\mathrm{Mg}^{+2}$, whereas no product was formed without a divalent cation. An inactive GGDEF domain

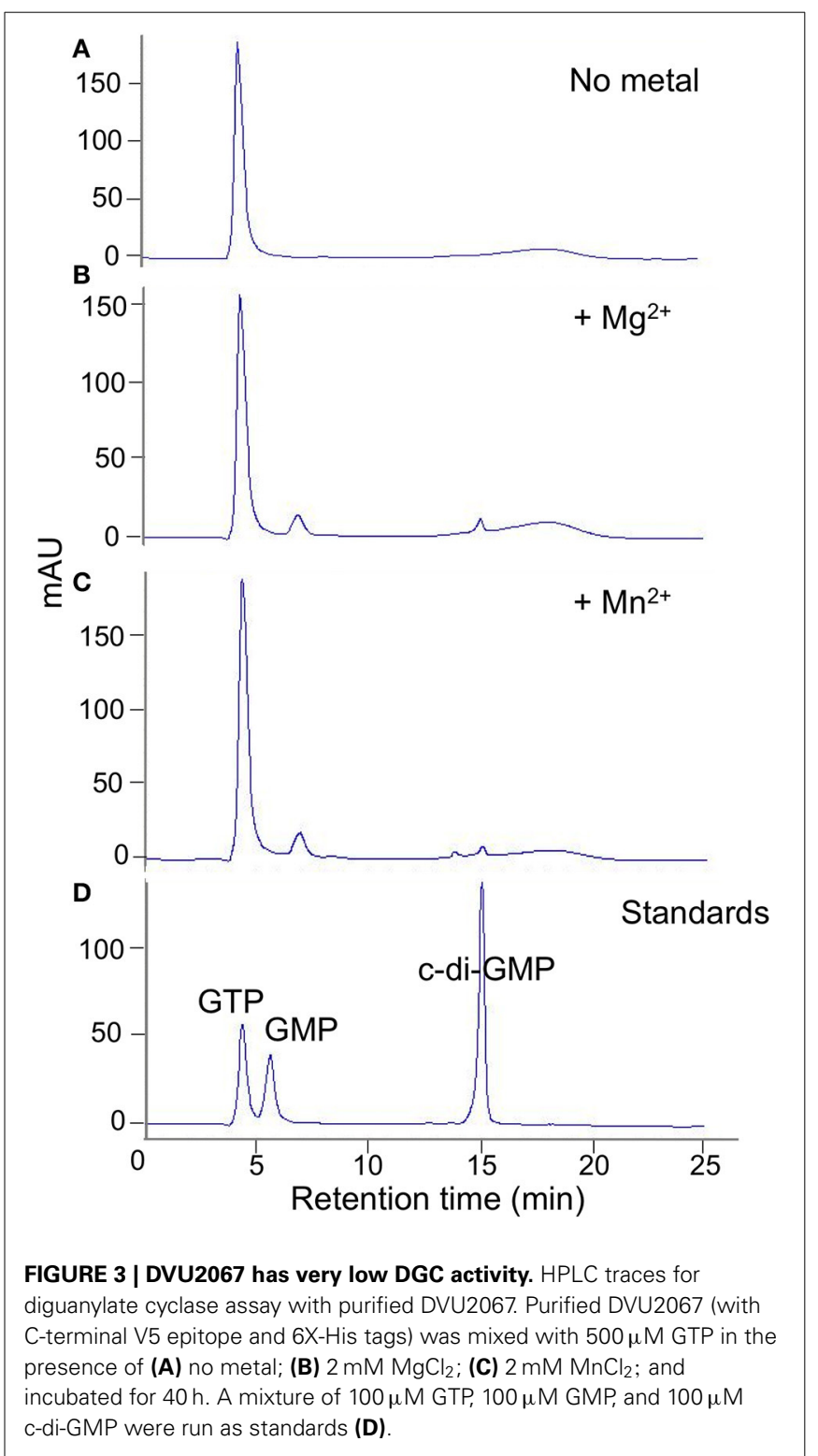




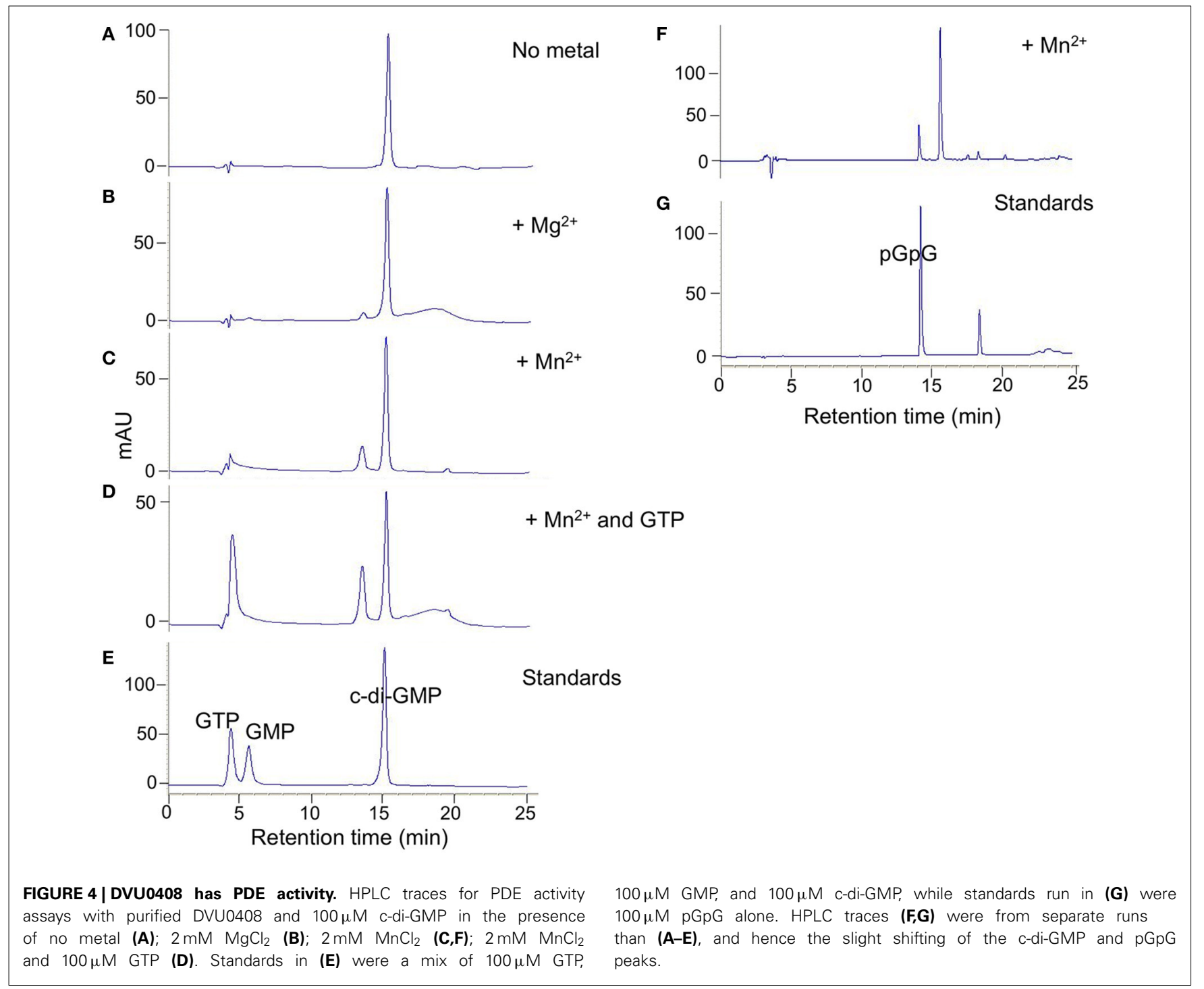

is often associated with allosteric activity upon GTP binding (Christen et al., 2005; Kazmierczak et al., 2006); therefore, we tested c-di-GMP hydrolysis activity with $\mathrm{Mn}^{+2}$ and GTP. There was an increase in the $\mathrm{pGpG}$ peak upon addition of GTP.

\section{RRs with HD-GYP domains have PDE activity}

Full length tagged HD-domain containing RRs were purified and tested for activity against the synthetic substrate bis- $p$ NPP as well as against c-di-GMP. The proteins had slow activity against bis$p$ NPP but no activity on c-di-GMP (not shown). For hydrolysis of bis- $p \mathrm{NPP}$, the proteins required $\mathrm{Mn}^{+2}$ and not $\mathrm{Mg}^{+2}$. We attempted to activate the proteins by phosphorylation with acetyl phosphate, however acetyl phosphate reacted with the $\mathrm{Mn}^{+2}$ and precipitated. Therefore, we cloned and purified only the respective tagless HD domains. All five purified HD domains showed PDE activity against bis- $p$ NPP in the presence of $\mathrm{Mn}^{+2}$, but not with $\mathrm{Mg}^{+2}$ and not in the absence of any divalent cation (Figure 5). The activity varied among the proteins. DVU2933 and DVUA0086 reached saturation in less than $2 \mathrm{~h}$, DVU0722 and
DVU1181 showed slower activity, and DVU0330 that lacks the GYP motif showed very low activity.

We then tested the purified HD domains for hydrolysis of c-diGMP (Figure 6). DVUA0086 protein had maximum activity and completely hydrolyzed c-di-GMP, with pGpG as the main product and a small amount of GMP. DVU0722 protein also hydrolyzed most of the c-di-GMP to pGpG. DVU2933 protein had lower activity, but again $\mathrm{pGpG}$ was the main product formed. DVU1181 and DVU0330 proteins had no activity against c-di-GMP under the conditions tested.

All five proteins were also tested against other possible substrates such as cyclic-di-AMP, cyclic-AMP, and cyclic-GMP. We did not detect any activity against these substrates (not shown). Providing pGpG as a substrate also showed only as much hydrolysis to GMP as was observed with c-di-GMP as a substrate.

\section{Congo Red assay}

We also tested all eight proteins for their ability to affect cellulose production in E. coli with a CR plate assay (Zogaj et al., 2001; 

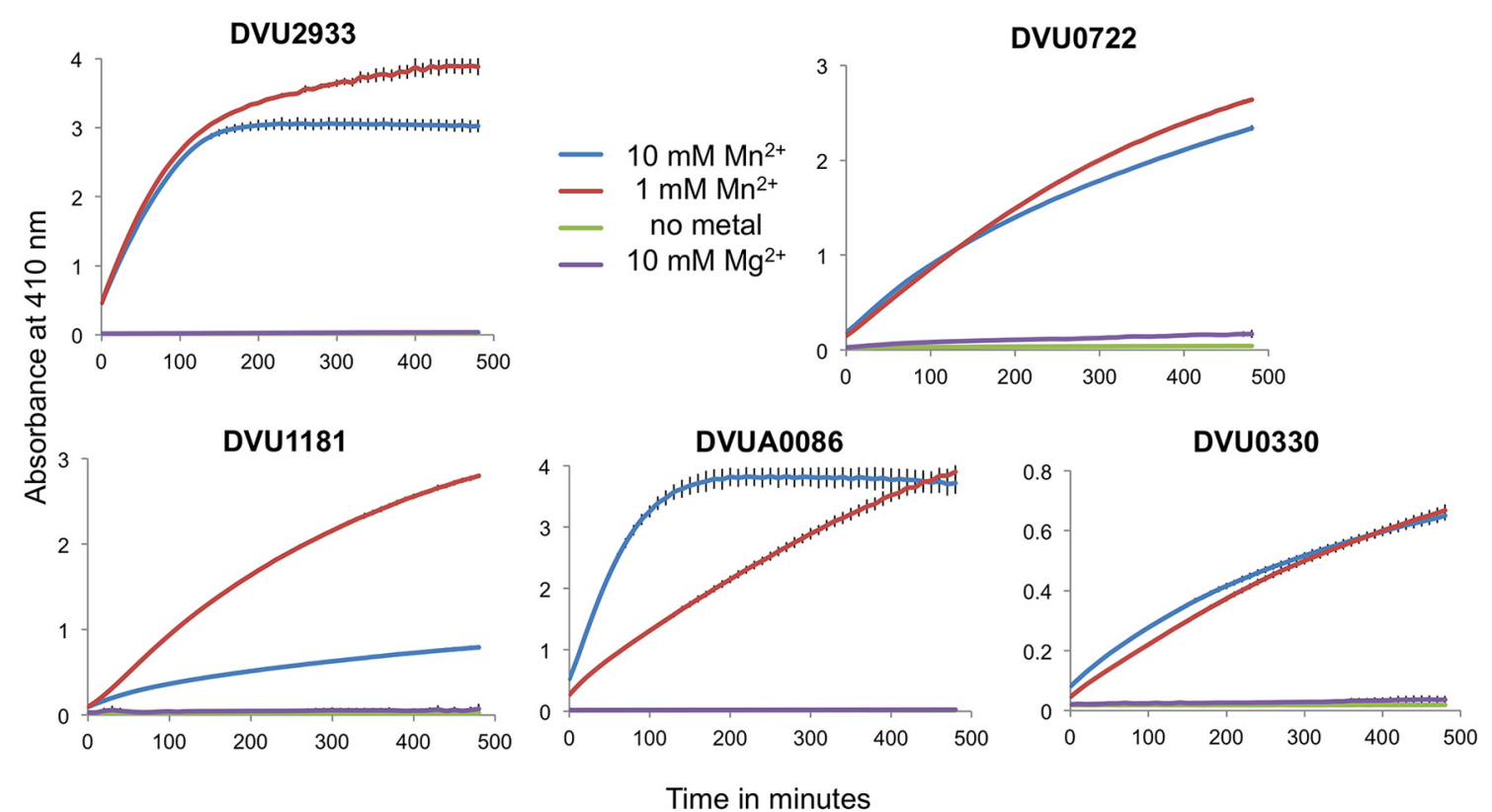

FIGURE 5 | Isolated HD-GYP domains have PDE activity with bis-pNPP. Isolated $\mathrm{HD}$ domains for the RRs were mixed with the synthetic substrate bis- $p N P P$ in the presence of either $10 \mathrm{mM}$ or $1 \mathrm{mM} \mathrm{MnCl}_{2}, 10 \mathrm{mM} \mathrm{MgCl}_{2}$ or no metal, and the product was measured spectrophotometrically at an absorbance of $410 \mathrm{~nm}$. Data are shown for the mean of triplicate reactions, with error bars indicating standard deviation. Note the differences in the scales on the $y$-axes.

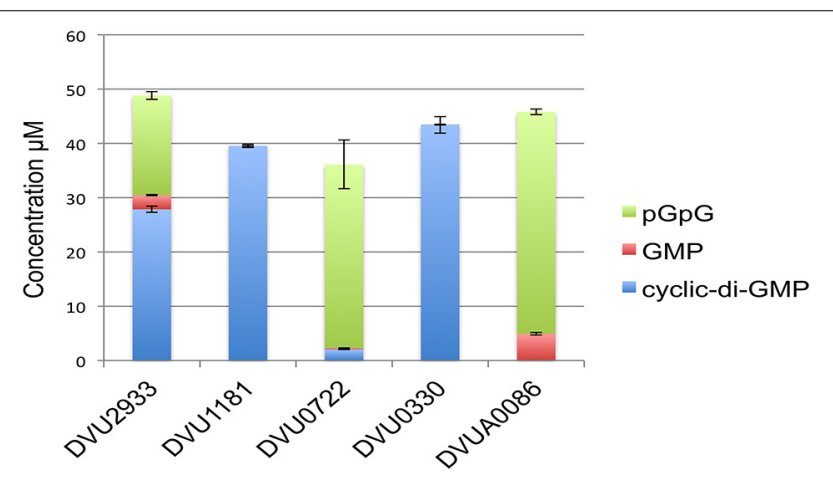

FIGURE 6 | C-di-GMP hydrolysis activity of HD-domain RRs. The graph shows the quantitative measurement of the amount of substrate (c-di-GMP) and products (pGpG and GMP) determined by HILIC-TOF MS analysis that were formed after incubation of isolated HD domains of each RR (7-10 $\mu \mathrm{g})$ with $100 \mu \mathrm{M}$ c-di-GMP. Concentrations were obtained by comparing peak areas to that of a standard curve. Error bars indicate standard deviations $(n=3)$.

Da Re and Ghigo, 2006). A negative result in this assay cannot be used conclusively; a positive response correlates with DGC activity of the expressed gene, and has been reported to evaluate heterologous proteins in E. coli (Liu et al., 2010; Ruiz et al., 2011). BL21 strains expressing tagged full length proteins were plated on CR plates \pm IPTG (Figure 7). The GGDEF domain containing DVU0636 formed bright pink colonies with CR when induced with IPTG, indicating that DVU0636 had DGC activity in vivo as well. The GGDEF domain containing RR DVU2067 formed orange colonies when induced with IPTG, although a

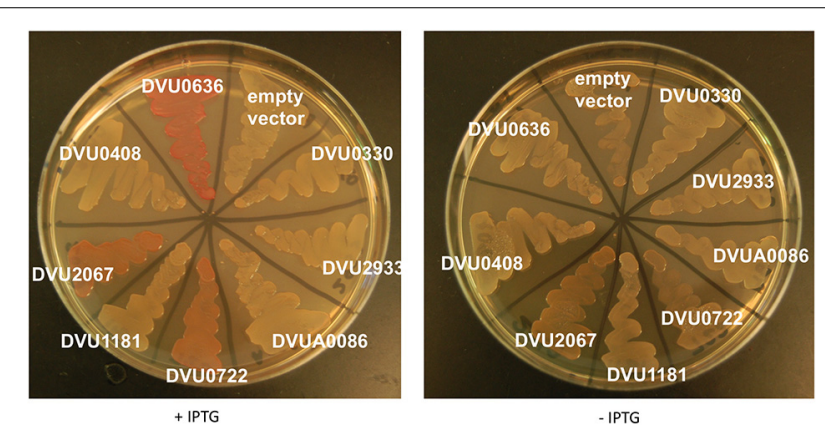

FIGURE 7 | E. coli Congo Red binding assay. E. coli BL21 strains expressing full length proteins with $\mathrm{C}$-terminal $\mathrm{V} 5$ and His tags were plated on LB-Carb plates with CR $(5 \mu \mathrm{g} / \mathrm{ml})$, with and without IPTG. Plates were incubated at room temperature and imaged after 4 days of growth.

slight orange tinge was visible in the absence of IPTG as well. Interestingly, the HD-GYP containing DVU0722 that we showed above to have PDE activity also showed orange colonies on CR plates + IPTG and, similar to DVU2067, a slight coloration was present in the absence of IPTG too.

\section{TRANSPOSON INSERTION MUTANT ANALYSIS}

To further examine physiological roles of these genes, we used mutants with transposon insertions into each of the $8 \mathrm{RR}$ genes that were available from a transposon mutant library.

\section{DVU2067 is required for optimal growth on LS4D}

We examined the strains for growth defects on LS4D medium. Of the two RRs with DGC activity, the strain with an insertion in 


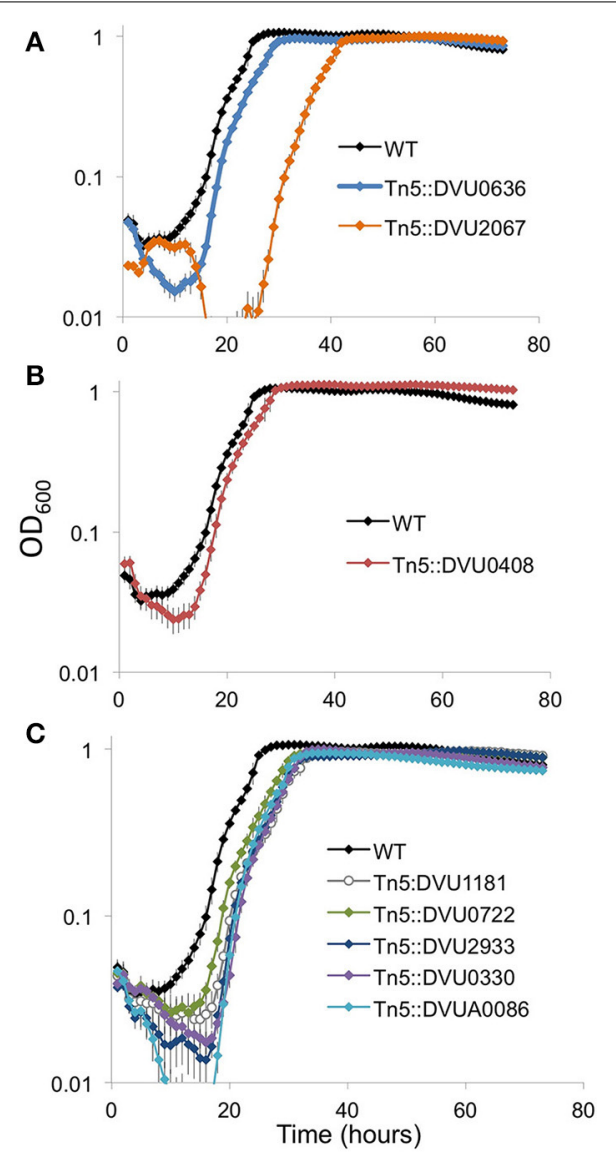

FIGURE 8 | Growth on LS4D for the transposon insertion mutants. Transposon mutants in the two GGDEF domain RR genes (A), the GGDEF-EAL RR (B), and the five HD domain RR genes (C) were compared to WT during growth on LS4D. Error bars indicate standard deviations $(n=4)$.

DVU2067 showed a prominent growth defect with a longer lag than WT (Figure 8A). Transposon mutant in DVU0636 showed a slightly slower growth and decreased cell mass yields than WT. An insertion mutant in DVU0408 (GGDEF-EAL) showed slightly higher maximal ODs than WT (Figure 8B). All mutants in HDdomain RRs grew similarly with a slightly longer lag and reduced cell densities than WT (Figure 8C).

\section{DVU0636 is required for optimal biofilm formation}

Biofilm formation is a common target of c-di-GMP regulation for numerous bacterial groups (Romling et al., 2013), but a relationship between second messenger molecules and biofilm formation has not been investigated previously in $\delta$-Proteobacteria. In general, proteins with GGDEF domains that synthesize c-diGMP promote biofilm formation (Romling et al., 2013). We had strong biochemical evidence for DGC activity with DVU0636 and therefore we examined the transposon mutant in DVU0636 for an effect on biofilm formation. We observed that although the mutant made some biofilm on glass slides, it made less total biofilm and the composition was very different compared to WT biofilm under steady-state conditions (Figure 9). The DVU0636 mutant biofilm had $>20$-fold lower protein $\left(\mu \mathrm{g} / \mathrm{cm}^{2}\right)$ compared to WT biofilm. Even though there was less biofilm, the mutant biofilm had approximately 2.3-fold more carbohydrate (hexose equivalents, $\mu \mathrm{g} / \mathrm{cm}^{2}$ ) compared to WT biofilm (Figure 9A). D. vulgaris WT makes biofilms that are composed more of protein filaments rather than carbohydrates (Clark et al., 2007) and these filaments were not observed in the mutant biofilm. Compared to WT biofilm that has a low carbohydrate to protein ratio $(\sim 0.03 \mu \mathrm{g} / \mu \mathrm{g})$, the $\Delta \mathrm{DVU} 0636$ biofilm had an elevated ratio of $1.7 \mu \mathrm{g} / \mu \mathrm{g}$ (Figure $9 \mathrm{~B}$ ). The FEM images of WT and mutant biofilm also showed biofilm that were drastically different (Figures 9C,D). The WT biofilms contained many more cells that likely accounted for the elevated protein levels, and carbohydrate was not obviously visible. However, the $\triangle$ DVU0636 biofilm had fewer visible cells with increased extracellular material that appeared to be carbohydrate. We complemented the mutant strain with a plasmid that expressed DVU0636 under a constitutive promoter. The complemented strain produced a biofilm that was more similar in composition to that of WT with more protein and less carbohydrate (C:P ratio of $0.2 \mu \mathrm{g} / \mu \mathrm{g}$ ) (Figure 9B). Electron micrographs of the complemented mutant biofilm also showed more cells than the mutant (Figure 9E).

\section{DISCUSSION}

The main finding of this study is the identification of a twocomponent signaling regulator, DVU0636, with significance in biofilm production. Previous work has demonstrated the importance of intracellular interactions and communication for the formation, maintenance, and structuring of biofilms (Burmolle et al., 2014) and this in turn can impact function, stability, and resiliency. However, little is known about anaerobic biofilms that respond differently to mass transport limitations of energy sources other than oxygen. D. vulgaris does not produce biofilms with much exopolysaccharide, rather the biofilms are composed of long protein filaments that appear to be flagella or modified flagella (Clark et al., 2007). In vitro, we confirmed DVU0636 to be a DGC, where we observed a metal dependence $\left(\mathrm{Mn}^{+2}\right.$ vs. $\left.\mathrm{Mg}^{+2}\right)$ on the products formed, though the identity and significance of these peaks remain to be explored. In vivo, the overexpression of DVU0636 heterologously in E. coli results in a predictable outcome of increased extracellular cellulose production as indicated by increased binding of the CR dye. In D. vulgaris, the role of DVU0636 may be in regulating other biofilm related enzymes, suggested by low protein levels in Tn5::DVU0636 biofilms, leading to a much greater C:P ratio relative to the WT or the complemented mutant (Figure 9). Possibly as a result of the non-optimal C:P ratio, the Tn5::DVU0636 biofilm has a "slimier" appearance and is easily disrupted (Figure 9D). There is likely an optimal ratio of protein and carbohydrate for biofilms that is required to maintain biofilm integrity yet maximize transfer of nutrients, and further work is needed to elucidate the environmental cues and regulated systems that bacteria use to coordinate biofilm growth with local environment.

The D. vulgaris genome encodes eight two-component RRs with putative c-di-GMP modulating domains. Aside from DVU0636, the other putative cyclase is DVU2067. Of these two RR DGCs, DVU2067 is more highly conserved (Table 2) and is 

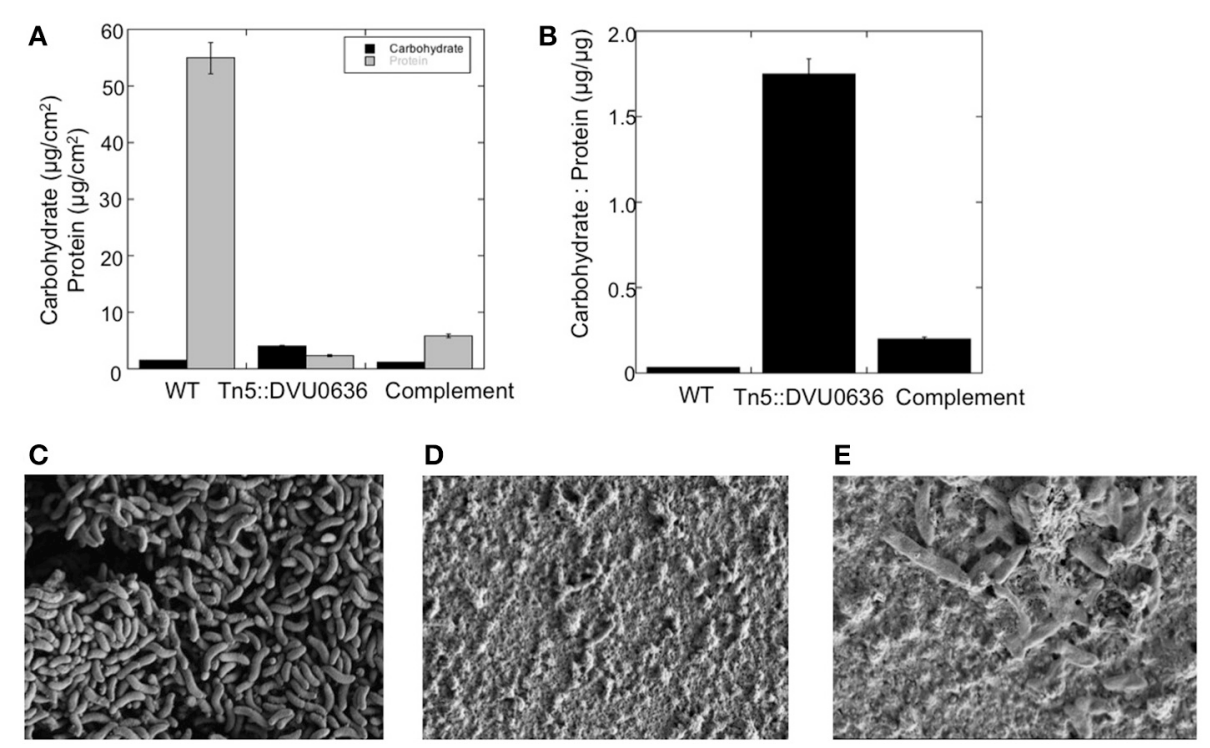

FIGURE 9 | Inactivation of DVU0636 affects biofilm formation. (A) The carbohydrate (black) and protein (gray) measurements for WT, Tn5::DVU0636 mutant and complemented strains. Measurements for carbohydrate and protein levels were measured in triplicate for biological duplicates. Error bars indicate standard error of the mean. (B) The carbohydrate to protein ratio ( $\mu \mathrm{g}$ hexose/ $\mu$ g protein) for wild-type, Tn5::DVU0636 and complemented mutant as steady-state biofilm. (C-E) Electron micrographs of biofilms of wild-type at $17,700 \times$ (C), mutant at $16,700 \times$ (D), and complemented mutant at $22,900 \times$ biofilms showing increased cells and decreased extracellular material for WT biofilm compared to mutant biofilm. also the enzyme needed for optimal growth typically observed under laboratory cultivation in LS4D medium. None of the other RR transposon mutants presented a significant growth defect in liquid culture. We observed very little in vitro activity for DVU2067, and it is possible that this protein requires phosphorylation. The in vivo CR plate assay showed that cells expressing DVU2067 gave orange coloration relative to cells expressing DVU0636, which were the more typically reported bright pink. The phenotypes observed for the two RR DGCs suggest that production of c-di-GMP does modulate important functions during both biofilm and planktonic growth.

Of the remaining six RRs, we confirmed PDE function for all but DVU0330. DVU0408, which contains both GGDEF and EAL domains, demonstrated turn over of c-di-GMP in vitro. The GGDEF domain of DVU0408 has a tyrosine instead of the conserved phenylalanine (Figure 1C), which could explain why this domain is inactive (Malone et al., 2007). However, DVU0408 has an active EAL domain that hydrolyses c-di-GMP into pGpG. Higher activity may be observed in an activated RR. Approximately 33\% of GGDEF- or EAL-containing proteins are hybrid proteins with both domains, and, among these hybrid proteins, more than $30 \%$ have an active EAL domain combined with an inactive GGDEF domain (Seshasayee et al., 2010). For DVU0408, we observed increased product formation in the presence of GTP, which supports the possibility that the inactive GGDEF domain may bind GTP and provide GTP-dependent control of PDE activity (Christen et al., 2005; Kazmierczak et al., 2006).

With the 4 HD-GYP domain RRs, we observed robust PDE activity with the synthetic bis-pNPP for all but activity with c-di-GMP for only 3. We also observed higher activity with the isolated domains rather than the full-length proteins suggesting that RR activation is necessary for maximal activity. The non-phosphorylated receiver domain of a Pseudomonas HD-GYP RR was shown to limit accessibility of the active site to c-di-GMP (Stelitano et al., 2013). The isolated HDGYP domain for DVU1181 was not active with c-di-GMP although it showed activity against bis-pNPP. Perhaps a more active conformation involving the receiver domain is required for activity with c-di-GMP. The HDOD domain, as present in DVU0330, is related to the HD superfamily of phosphohydrolases (Aravind and Koonin, 1998) but lacks the key active site residues (Galperin, 2006). An HDOD RR, GsmR, was recently characterized from Xanthomonas campestris, and found to regulate the expression of motility related genes. GsmR lacked the conserved His in the active site, and also lacked phosphatase or phosphodiesterase activity (Liu et al., 2013). DVU0330 has the conserved HD active site residues (Figure 1C), and here we showed that the isolated domain has weak PDE activity with bis- $p$ NPP and none with c-di-GMP or any of the other substrates.

We also observed that for DVU0408, as well as the three active HD-GYP RRs, the hydrolysis product was primarily pGpG. For EAL domains it has been reported that $\mathrm{pGpG}$ is the primary product, however GMP is reported as the predominant product for HD-GYP domains (Ryan et al., 2006; Romling et al., 2013). Some recent studies on other HD-GYP proteins also report on pGpG being the main product (Stelitano et al., 2013), and they suggest the possibility of $\mathrm{pGpG}$ being a signaling molecule in its own right. D. vulgaris Hildenborough is among the genomes with the highest number of HD-GYP domain genes encoded (Galperin et al., 2010) with a total of 14 genes, and it would be interesting to 


\section{高}

Desulfovibrio acrylicus

Desulfovibrio aespoeensis Aspo-2

Desulfovibrio africanus DSM 2603

Desulfovibrio africanus PCS

Desulfovibrio africanus Walvis Bay

Desulfovibrio alaskensis DSM 16109

Desulfovibrio alaskensis G20

Desulfovibrio aminophilus

Desulfovibrio bastinii

Desulfovibrio desulfuricans aestuarii

Desulfovibrio desulfuricans desulfuricans 27774

Desulfovibrio desulfuricans desulfuricans DSM 642

Desulfovibrio fructosovorans JJ

Desulfovibrio gigas

Desulfovibrio hydrothermalis

Desulfovibrio inopinatus

Desulfovibrio longus

Desulfovibrio magneticus Maddingley

Desulfovibrio magneticus RS-1

Desulfovibrio oxyclinae

Desulfovibrio piezophilus

Desulfovibrio piger

Desulfovibrio putealis

Desulfovibrio salexigens

Desulfovibrio sp. 3_1_syn3

Desulfovibrio sp. 6_1_46AFAA

Desulfovibrio sp. A2

Desulfovibrio sp. FW1012B

Desulfovibrio sp. ND132

Desulfovibrio sp. U5L

Desulfovibrio termitidis HI1

Desulfovibrio vulgaris Miyazaki F

Desulfovibrio vulgaris vulgaris DP4

Desulfovibrio vulgaris vulgaris Hildenborough

Desulfovibrio zosterae

$+$

$+$

$+$

+
+
+
+
+
+

\begin{tabular}{|c|c|c|c|c|c|}
\hline 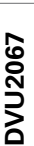 & 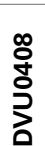 & $\underset{⿱ 乛}{\stackrel{\infty}{5}}$ & 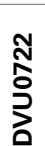 & 趈 & \begin{tabular}{l}
0 \\
0 \\
0 \\
0 \\
\hdashline \\
\hdashline
\end{tabular} \\
\hline
\end{tabular}

$+$

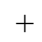

$+$

$+$

$+$

$+$

$+$

$+\quad+$

$+\quad+$

$++$

$+$

$++$

$+\quad+$

$+$

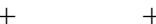

$+$

$+$

$\begin{array}{llll} & & + & + \\ & & & + \\ & & & + \\ + & + & + & + \\ + & + & + & + \\ & + & & + \\ & & & \\ + & & & +\end{array}$

$+$

$+$

$+$

$+$

$+$

$+\quad+$

$+$

$+$

$$
+
$$$$
+
$$

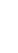

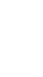$$
+
$$

\section{?}

$$
\text { . }
$$

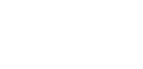$$
+
$$$$
\begin{array}{lll}
+ & + & + \\
+ & & + \\
+ & + & + \\
+ & & + \\
+ & & + \\
+ & + & +
\end{array}
$$$$
+
$$$$
+
$$$$
+
$$$$
+
$$$$
+
$$$$
+
$$

Orthologs were determined using the "find homolog" tool on the IMG website (Integrated Microbial Genomes) (Markowitz et al., 2012).

know which perform the incomplete hydrolysis of c-di-GMP to pGpG vs. completely to GMP.

As expected, the CR plate assay with E. coli strains expressing PDE RRs gave white colonies with or without IPTG. The interesting exception was the strain expressing DVU0722, which had orange coloration. This was unexpected as DVU0722 has PDE activity in vitro and hydrolyzes c-di-GMP. We speculate that DVU0722 interacts with other proteins in E. coli and ultimately leads to increased cellulose production.

Gene knockout strains of PDE RRs resulted in no impact on growth in liquid cultures. Additional experimentation is required to identify the phenotypes that involve the other RRs. Genetic data are available for only a few HD-GYP proteins from pathogens, and none from environmental isolates. RpfG from Xanthomonas campestris promotes synthesis of virulence factors and affects biofilm formation and motility (Ryan et al., 2010, 2012). The Borrelia burgdorferi PdeB controls motility and promotes virulence in ticks (Sultan et al., 2011). Two HD-GYP domain proteins from Pseudomonas aeruginosa control swarming motility and production of virulence factors (Ryan et al., 2009). However, other studies conducted in D. vulgaris Hildenborough do shed some light on potential conditions under which the function of these RRs may be relevant. For example, in a recent evaluation of all transcriptionally acting two-component RRs in D. vulgaris (Rajeev et al., 2011), DVU0408 was found to be the target for the RR DVU1063, which also targets several flagellar genes. 
A Exponential

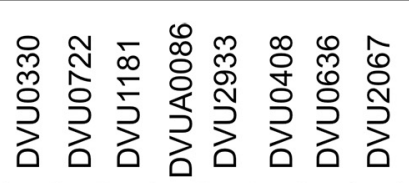

Stationary vs
Exponential

T5 vs T1

T6 vs T1

T7 vs T1

T8 vs T1

T9 vs T1

T5 vs T4

T6 vs T4

T7 vs T4

T8 vs T4

T9 vs T4
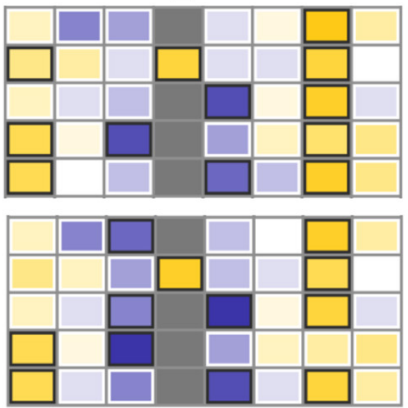

B CooA- vs WT on PS

Biofilm vs log phase

C Bioreactor vs log phase

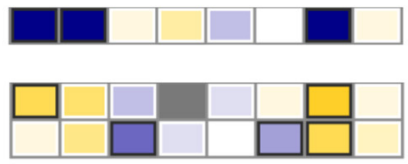

$1 \mathrm{mM} \mathrm{H}_{2} \mathrm{O}_{2}$ Time 0

Time $30 \mathrm{~min}$

Time $60 \mathrm{~min}$

D

Time $120 \mathrm{~min}$

Time $240 \mathrm{~min}$ Time $480 \mathrm{~min}$

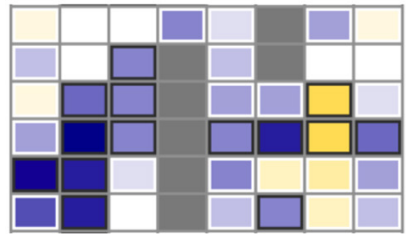

MP- vs WT at 30

E

MP- vs WT at 60

MP- vs WT at 120

MP- vs WT at 240

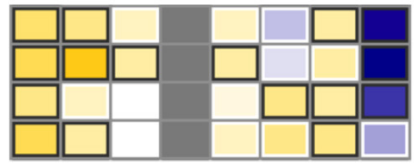

sulfate (Rajeev et al., 2012). (C) Biofilm and bioreactor samples vs. log

FIGURE 10 | Transcriptomics data showing relevant conditions for differential expression of the 8 RRs. (A) Stationary vs. Exponential phase where T1-T2 are exponential phases, T3-T4 are late exponential phases, T5 is early stationary, and T9 is late stationary (Clark et al., 2006). (B) CooA mutant (Deletion in DVU2097) vs. WT on pyruvate phase cells (Clark et al., 2012). (D) Temporal analysis of exposure to $1 \mathrm{mM}$ hydrogen peroxide (Zhou et al., 2010). (E) pDV1- strain vs. WT (unpublished). Data were visualized using MicrobesOnline (Dehal et al., 2010).
DVU0408 may thus be involved indirectly in cellular motility. A knockout of this gene however had motility in wet mounts as well as in soft agar plates (data not shown). In the same study (Rajeev et al., 2011), DVU2933 was found to be part of a five-gene operon that also encodes a histidine kinase and another RR, DVU2934, which is a DNA binding RR that targets the $l p x C$ gene involved in lipid A synthesis.

A review of available transcriptomics measurements in D. vulgaris (Figure 10) shows increased expression of DVU0636 (and DVU0330) transcripts in stationary phase vs. exponential growth stages (Clark et al., 2006). DVU0636 was also upregulated during biofilm growth (Clark et al., 2012), which is again consistent with our results. DVU0636 was also increased in expression during peroxide exposure, in contrast to DVU1181, DVU0722, and DVU2933, which were decreased in expression in this condition (Zhou et al., 2010). In a more environmentally relevant growth regime, defense against peroxide and other oxidative stresses may include the production of biofilms and may explain the increase in DVU0636 transcripts. Further, DVU0636 (and DVU0330,
DVU0722) were decreased in expression, while DVU2067 was increased in expression in a CooA mutant, which lacks the gene DVU2097 that acts as a carbon monoxide sensor. Transcriptomic analysis of the CooA mutant showed changes similar to that seen in WT when exposed to CO including a decrease in expression of Fur regulon genes, and was suggested to have been due to increased levels of endogenous $\mathrm{CO}$ and oxidative stress (Rajeev et al., 2012). Conversely, DVU0636 is upregulated, while DVU2067 is downregulated in the pDV1-minus strain, relative to the wild type. The pDV1 minus strain lacks the native $200-\mathrm{kb}$ plasmid present in wild type $D$. vulgaris Hildenborough and has a reported defect in attachment and biofilm formation (Clark et al., 2007) and is also missing the DVUA0086 RR. More experimentation is required to prove if the regulation and function of these RRs are interconnected or interdependent.

\section{CONCLUSIONS}

This is the first demonstration of PDE and DGC activity in a sulfate-reducing bacterium. We were most successful in 
identifying conditions under which the two DGC RRs are important, though they may have a role in other conditions also. The most conserved candidate, DVU2067, generated a growth defective strain in planktonic cultures. The less conserved, DVU0636, had no impact during growth in liquid cultures but had a clear role in biofilm production. The impact on biofilm growth manifested in altered macromolecular composition that caused decreased biofilm maintenance with elevated carbohydrate levels. The PDE RRs have no clear roles in WT planktonic growth, though some ancillary data links the dual domain DVU0408 with flagellar genes and PDEs to stress responses. Further studies will reveal the roles they play in other aspects of $D$. vulgaris physiology.

\section{ACKNOWLEDGMENTS}

We would like to thank Amy Chen and Kavya Siddartha for technical assistance. This work is part of ENIGMA, a Scientific Focus Area Program supported by the US Department of Energy, Office of Science, Office of Biological and Environmental Research, Genomics: GTL Foundational Science through contract DE-AC02-05CH11231 between Lawrence Berkeley National Laboratory and the U.S. Department of Energy. A portion of this work was supported by the U.S. Department of Energy Office of Science, Office of Biological and Environmental Research, Genomics Program:GTL BioHydrogen Production and BioEthanol contract DE-FG02-08346469.

\section{REFERENCES}

Aravind, L., and Koonin, E. V. (1998). The HD domain defines a new superfamily of metal-dependent phosphohydrolases. Trends Biochem. Sci. 23, 469-472. doi: 10.1016/S0968-0004(98)01293-6

Beyenal, H., Sani, R. K., Peyton, B. M., Dohnalkova, A. C., Amonette, J. E., and Lewandowski, Z. (2004). Uranium immobilization by sulfate-reducing biofilms. Environ. Sci. Technol. 38, 2067-2074. doi: 10.1021/es0348703

Bokinsky, G., Baidoo, E. E., Akella, S., Burd, H., Weaver, D., Alonso-Gutierrez, J., et al. (2013). HipA-triggered growth arrest and $\beta$-lactam tolerance in Escherichia coli are mediated by RelA-dependent ppGpp synthesis. J. Bacteriol. 195, 3173-3182. doi: 10.1128/JB.02210-12

Brandis, A., and Thauer, R. K. (1981). Growth of Desulfovibrio species on hydrogen and sulfate as sole energy-source. J. Gen. Microbiol. 126, 249-252. doi: 10.1099/00221287-126-1-249

Burmolle, M., Ren, D., Bjarnsholt, T., and Sorensen, S. J. (2014). Interactions in multispecies biofilms: do they actually matter? Trends Microbiol. 22, 84-91. doi: 10.1016/j.tim.2013.12.004

Chaplin, M. F. (1986). "Monosaccharides," in Carbohydrate Analysis, eds M. F. Chaplin and J. F. Kennedy (Oxford: IRL Press), 1-4.

Christen, M., Christen, B., Folcher, M., Schauerte, A., and Jenal, U. (2005). Identification and characterization of a cyclic di-GMP-specific phosphodiesterase and its allosteric control by GTP. J. Biol. Chem. 280, 30829-30837. doi: 10.1074/jbc.M504429200

Clark, M. E., Edelmann, R. E., Duley, M. L., Wall, J. D., and Fields, M. W. (2007). Biofilm formation in Desulfovibrio vulgaris Hildenborough is dependent upon protein filaments. Environ. Microbiol. 9, 2844-2854. doi: 10.1111/j.14622920.2007.01398.x

Clark, M. E., He, Q., He, Z., Huang, K. H., Alm, E. J., Wan, X. F., et al. (2006). Temporal transcriptomic analysis as Desulfovibrio vulgaris Hildenborough transitions into stationary phase during electron donor depletion. Appl. Environ. Microbiol. 72, 5578-5588. doi: 10.1128/AEM. 00284-06

Clark, M. E., He, Z., Redding, A. M., Joachimiak, M. P., Keasling, J. D., Zhou, J. Z., et al. (2012). Transcriptomic and proteomic analyses of Desulfovibrio vulgaris biofilms: carbon and energy flow contribute to the distinct biofilm growth state. BMC Genomics 13:138. doi: 10.1186/1471-2164-13-138
Da Re, S., and Ghigo, J. M. (2006). A CsgD-independent pathway for cellulose production and biofilm formation in Escherichia coli. J. Bacteriol. 188, 3073-3087. doi: 10.1128/JB.188.8.3073-3087.2006

Dehal, P. S., Joachimiak, M. P., Price, M. N., Bates, J. T., Baumohl, J. K., Chivian, D., et al. (2010). MicrobesOnline: an integrated portal for comparative and functional genomics. Nucleic Acids Res. 38, D396-D400. doi: 10.1093/nar/gkp919

Faybishenko, B., Hazen, T. C., Long, P. E., Brodie, E. L., Conrad, M. E., Hubbard, S. S., et al. (2008). In situ long-term reductive bioimmobilization of $\mathrm{Cr}(\mathrm{VI})$ in groundwater using hydrogen release compound. Environ. Sci. Technol. 42, 8478-8485. doi: 10.1021/es801383r

Fels, S. R., Zane, G. M., Blake, S. M., and Wall, J. D. (2013). Rapid transposon liquid enrichment sequencing (TnLE-seq) for gene fitness evaluation in underdeveloped bacterial systems. Appl. Environ. Microbiol. 79, 7510-7517. doi: 10.1128/AEM.02051-13

Galperin, M. Y. (2006). Structural classification of bacterial response regulators: diversity of output domains and domain combinations. J. Bacteriol. 188, 4169-4182. doi: 10.1128/JB.01887-05

Galperin, M. Y., Higdon, R., and Kolker, E. (2010). Interplay of heritage and habitat in the distribution of bacterial signal transduction systems. Mol. Biosyst. 6, 721-728. doi: 10.1039/b908047c

Gibson, D. G., Young, L., Chuang, R. Y., Venter, J. C., Hutchison, C. A. 3rd, and Smith, H. O. (2009). Enzymatic assembly of DNA molecules up to several hundred kilobases. Nat. Methods 6, 343-345. doi: 10.1038/nmeth.1318

Golovanov, A. P., Hautbergue, G. M., Wilson, S. A., and Lian, L. Y. (2004). A simple method for improving protein solubility and long-term stability. J. Am. Chem. Soc. 126, 8933-8939. doi: 10.1021/ja049297h

Heidelberg, J. F., Seshadri, R., Haveman, S. A., Hemme, C. L., Paulsen, I. T., Kolonay, J. F., et al. (2004). The genome sequence of the anaerobic, sulfatereducing bacterium Desulfovibrio vulgaris Hildenborough. Nat. Biotechnol. 22 , 554-559. doi: 10.1038/nbt959

Hengge, R. (2009). Principles of c-di-GMP signalling in bacteria. Nat. Rev. Microbiol. 7, 263-273. doi: 10.1038/nrmicro2109

Hillesland, K. L., and Stahl, D. A. (2010). Rapid evolution of stability and productivity at the origin of a microbial mutualism. Proc. Natl. Acad. Sci. U.S.A. 107, 2124-2129. doi: 10.1073/pnas.0908456107

Kazakov, A. E., Rajeev, L., Luning, E. G., Zane, G. M., Siddartha, K., Rodionov, D. A., et al. (2013a). New family of tungstate-responsive transcriptional regulators in sulfate-reducing bacteria. J. Bacteriol. 195, 4466-4475. doi: 10.1128/JB. 00679-13

Kazakov, A. E., Rodionov, D. A., Price, M. N., Arkin, A. P., Dubchak, I., and Novichkov, P. S. (2013b). Transcription factor family-based reconstruction of singleton regulons and study of the Crp/Fnr, ArsR, and GntR families in Desulfovibrionales genomes. J. Bacteriol. 195, 29-38. doi: 10.1128/JB.01977-12

Kazmierczak, B. I., Lebron, M. B., and Murray, T. S. (2006). Analysis of FimX, a phosphodiesterase that governs twitching motility in Pseudomonas aeruginosa. Mol. Microbiol. 60, 1026-1043. doi: 10.1111/j.1365-2958.2006. 05156.x

Keller, K. L., Rapp-Giles, B. J., Semkiw, E. S., Porat, I., Brown, S. D., and Wall, J. D. (2014). New model for electron flow for sulfate reduction in Desulfovibrio alaskensis G20. Appl. Environ. Microbiol. 80, 855-868. doi: 10.1128/AEM. 02963-13

Lee, W., Lewandowski, Z., Nielsen, P. H., and Hamilton, W. A. (1995). Role of sulfate-reducing bacteria in corrosion of mild steel: a review. Biofouling 8, 165-194. doi: 10.1080/08927019509378271

Liu, N., Pak, T., and Boon, E. N. (2010). Characterization of a diguanylate cyclase from Shewanella woodyi with cyclase and phosphodiesterase activities. Mol. Biosyst. 6, 1561-1564. doi: 10.1039/C002246B

Liu, Y.-F., Liao, C.-T., Song, W.-L., Hsu, P.-C., Du, S.-C., Lo, H.-H., et al. (2013). GsmR, a response regulator with an HD-related output domain in Xanthomonas campestris, is positively controlled by $\mathrm{Clp}$ and is involved in the expression of genes responsible for flagellum synthesis. FEBS J. 280, 199-213. doi: 10.1111/febs.12061

Malone, J. G., Williams, R., Christen, M., Jenal, U., Spiers, A. J., and Rainey, P. B. (2007). The structure-function relationship of WspR, a Pseudomonas fluorescens response regulator with a GGDEF output domain. Microbiology 153, 980-994. doi: 10.1099/mic.0.2006/002824-0

Markowitz, V. M., Chen, I. M., Palaniappan, K., Chu, K., Szeto, E., Grechkin, Y., et al. (2012). IMG: the Integrated Microbial Genomes database and comparative analysis system. Nucleic Acids Res. 40, D115-D122. doi: 10.1093/nar/gkr1044 
Paul, R., Weiser, S., Amiot, N. C., Chan, C., Schirmer, T., Giese, B., et al. (2004). Cell cycle-dependent dynamic localization of a bacterial response regulator with a novel di-guanylate cyclase output domain. Genes Dev. 18, 715-727. doi: $10.1101 /$ gad. 289504

Rajeev, L., Hillesland, K. L., Zane, G. M., Zhou, A., Joachimiak, M. P., He, Z., et al. (2012). Deletion of the Desulfovibrio vulgaris carbon monoxide sensor invokes global changes in transcription. J. Bacteriol. 194, 5783-5793. doi: 10.1128/JB.00749-12

Rajeev, L., Luning, E. G., Dehal, P. S., Price, M. N., Arkin, A. P., and Mukhopadhyay, A. (2011). Systematic mapping of two component response regulators to gene targets in a model sulfate reducing bacterium. Genome Biol. 12, R99. doi: 10.1186/gb-2011-12-10-r99

Ray, J., Keller, K. L., Catena, M., Juba, T. R., Zemla, M., Rajeev, L., et al. (2014). Exploring the role of CheA3 in Desulfovibrio vulgaris Hildenborough motility. Front. Microbiol. 5:77. doi: 10.3389/fmicb.2014.00077

Rodionov, D. A., Dubchak, I., Arkin, A., Alm, E., and Gelfand, M. S. (2004). Reconstruction of regulatory and metabolic pathways in metal-reducing deltaproteobacteria. Genome Biol. 5:R90. doi: 10.1186/gb-2004-5-11-r90

Romling, U., Galperin, M. Y., and Gomelsky, M. (2013). Cyclic di-GMP: the first 25 years of a universal bacterial second messenger. Microbiol. Mol. Biol. Rev. 77, 1-52. doi: 10.1128/MMBR.00043-12

Ross, P., Weinhouse, H., Aloni, Y., Michaeli, D., Weinberger-Ohana, P., Mayer, R., et al. (1987). Regulation of cellulose synthesis in Acetobacter xylinum by cyclic diguanylic acid. Nature 325, 279-281.

Ruiz, L. M., Castro, M., Barriga, A., Jerez, C. A., and Guiliani, N. (2011). The extremophile Acidithiobacillus ferrooxidans possesses a cyclic-di-GMP signaling pathway that could play a significant role during bioleaching of minerals. Lett. Appl. Microbiol. 54, 133-139. doi: 10.1111/j.1472-765X.2011.03180.x

Ryan, R. P., Fouhy, Y., Lucey, J. F., Crossman, L. C., Spiro, S., He, Y. W., et al. (2006). Cell-cell signaling in Xanthomonas campestris involves an HD-GYP domain protein that functions in cyclic di-GMP turnover. Proc. Natl. Acad. Sci. U.S.A. 103, 6712-6717. doi: 10.1073/pnas.0600345103

Ryan, R. P., Lucey, J., O’donovan, K., Mccarthy, Y., Yang, L., Tolker-Nielsen, T., et al. (2009). HD-GYP domain proteins regulate biofilm formation and virulence in Pseudomonas aeruginosa. Environ. Microbiol. 11, 1126-1136. doi: 10.1111/j.1462-2920.2008.01842.x

Ryan, R. P., Mccarthy, Y., Andrade, M., Farah, C. S., Armitage, J. P., and Dow, J. M. (2010). Cell-cell signal-dependent dynamic interactions between HD-GYP and GGDEF domain proteins mediate virulence in Xanthomonas campestris. Proc. Natl. Acad. Sci. U.S.A. 107, 5989-5994. doi: 10.1073/pnas. 0912839107

Ryan, R. P., Mccarthy, Y., Kiely, P. A., O'connor, R., Farah, C. S., Armitage, J. P., et al. (2012). Dynamic complex formation between HD-GYP, GGDEF and PilZ domain proteins regulates motility in Xanthomonas campestris. Mol. Microbiol. 86, 557-567. doi: $10.1111 / \mathrm{mmi} .12000$

Ryjenkov, D. A., Tarutina, M., Moskvin, O. V., and Gomelsky, M. (2005). Cyclic diguanylate is a ubiquitous signaling molecule in bacteria: insights into biochemistry of the GGDEF protein domain. J. Bacteriol. 187, 1792-1798. doi: 10.1128/JB.187.5.1792-1798.2005

Schirmer, T., and Jenal, U. (2009). Structural and mechanistic determinants of c-di-GMP signalling. Nat. Rev. Microbiol. 7, 724-735. doi: 10.1038/ nrmicro2203

Schmidt, A. J., Ryjenkov, D. A., and Gomelsky, M. (2005). The ubiquitous protein domain EAL is a cyclic diguanylate-specific phosphodiesterase: enzymatically active and inactive EAL domains. J. Bacteriol. 187, 4774-4781. doi: 10.1128/JB.187.14.4774-4781.2005

Seshasayee, A. S., Fraser, G. M., and Luscombe, N. M. (2010). Comparative genomics of cyclic-di-GMP signalling in bacteria: post-translational regulation and catalytic activity. Nucleic Acids Res. 38, 5970-5981. doi: 10.1093/nar/gkq382

Simm, R., Morr, M., Kader, A., Nimtz, M., and Romling, U. (2004). GGDEF and EAL domains inversely regulate cyclic di-GMP levels and transition from sessility to motility. Mol. Microbiol. 53, 1123-1134. doi: 10.1111/j.13652958.2004.04206.x
Solano, C., Garcia, B., Latasa, C., Toledo-Arana, A., Zorraquino, V., Valle, J., et al. (2009). Genetic reductionist approach for dissecting individual roles of GGDEF proteins within the c-di-GMP signaling network in Salmonella. Proc. Natl. Acad. Sci. U.S.A. 106, 7997-8002. doi: 10.1073/pnas.0812573106

Stelitano, V., Giardina, G., Paiardini, A., Castiglione, N., Cutruzzola, F., and Rinaldo, S. (2013). C-di-GMP hydrolysis by Pseudomonas aeruginosa HD-GYP phosphodiesterases: analysis of the reaction mechanism and novel roles for pGpG. PLoS ONE 8:e74920. doi: 10.1371/journal.pone.0074920

Sultan, S. Z., Pitzer, J. E., Boquoi, T., Hobbs, G., Miller, M. R., and Motaleb, M. A. (2011). Analysis of the HD-GYP domain cyclic dimeric GMP phosphodiesterase reveals a role in motility and the enzootic life cycle of Borrelia burgdorferi. Infect. Immun. 79, 3273-3283. doi: 10.1128/IAI.05153-11

Tan, H., West, J. A., Ramsay, J. P., Monson, R. E., Griffin, J. L., Toth, I. K., et al. (2014). Comprehensive overexpression analysis of cyclic-di-GMP signalling proteins in the phytopathogen Pectobacterium atrosepticum reveals diverse effects on motility and virulence phenotypes. Microbiology 160, 1427-1439. doi: 10.1099/mic.0.076828-0

Tartof, K. D., and Hobbs, C. A. (1987). Improved media for growing plasmid and cosmid clones. Bethesda Res. Lab. Focus 9, 12.

Wang, Y., Xu, J., Chen, A., Wang, Y., Zhu, J., Yu, G., et al. (2010). GGDEF and EAL proteins play different roles in the control of Sinorhizobium meliloti growth, motility, exopolysaccharide production, and competitive nodulation on host alfalfa. Acta Biochim. Biophys. Sin. (Shanghai). 42, 410-417. doi: 10.1093/abbs/gmq034

Zane, G. M., and Wall, J. D. (2013). Desulfovibrio vulgaris Hildenborough Transposon Mutant Library [Online]. Available online at: http:// desulfovibriomaps.biochem.missouri.edu/mutants/

Zane, G. M., Yen, H. C., and Wall, J. D. (2010). Effect of the deletion of qmoABC and the promoter-distal gene encoding a hypothetical protein on sulfate reduction in Desulfovibrio vulgaris Hildenborough. Appl. Environ. Microbiol. 76, 5500-5509. doi: 10.1128/AEM.00691-10

Zhou, A., He, Z., Redding-Johanson, A. M., Mukhopadhyay, A., Hemme, C. L., Joachimiak, M. P., et al. (2010). Hydrogen peroxide-induced oxidative stress responses in Desulfovibrio vulgaris Hildenborough. Environ. Microbiol. 12, 2645-2657. doi: 10.1111/j.1462-2920

Zhou, J., He, Q., Hemme, C. L., Mukhopadhyay, A., Hillesland, K., Zhou, A., et al. (2011). How sulphate-reducing microorganisms cope with stress: lessons from systems biology. Nat. Rev. Microbiol. 9, 452-466. doi: 10.1038/ nrmicro2575

Zogaj, X., Nimtz, M., Rohde, M., Bokranz, W., and Romling, U. (2001). The multicellular morphotypes of Salmonella typhimurium and Escherichia coli produce cellulose as the second component of the extracellular matrix. Mol. Microbiol. 39, 1452-1463. doi: 10.1046/j.1365-2958.2001.02337.x

Conflict of Interest Statement: The authors declare that the research was conducted in the absence of any commercial or financial relationships that could be construed as a potential conflict of interest.

Received: 29 May 2014; accepted: 09 July 2014; published online: 29 July 2014.

Citation: Rajeev L, Luning EG, Altenburg S, Zane GM, Baidoo EEK, Catena M, Keasling JD, Wall JD, Fields MW and Mukhopadhyay A (2014) Identification of a cyclic-di-GMP-modulating response regulator that impacts biofilm formation in a model sulfate reducing bacterium. Front. Microbiol. 5:382. doi: 10.3389/fmicb. 2014.00382

This article was submitted to Terrestrial Microbiology, a section of the journal Frontiers in Microbiology.

Copyright (๑) 2014 Rajeev, Luning, Altenburg, Zane, Baidoo, Catena, Keasling, Wall, Fields and Mukhopadhyay. This is an open-access article distributed under the terms of the Creative Commons Attribution License (CC BY). The use, distribution or reproduction in other forums is permitted, provided the original author(s) or licensor are credited and that the original publication in this journal is cited, in accordance with accepted academic practice. No use, distribution or reproduction is permitted which does not comply with these terms. 